\title{
Vertreterversammlung der KZVB stärkt Ehrenamt und Demokratie
}

\author{
Die Delegierten des Freien Verbandes Deutscher Zahnärzte (FVDZ) in Bayern setzen ihre \\ Wahlversprechen konsequent um. Das war das wichtigste Ergebnis der Vertreterversammlung \\ (VV) der Kassenzahnärztlichen Vereinigung Bayerns, die im Februar im Zahnärztehaus in Mün- \\ chen stattfand.
}

Ein Antrag auf Änderung der Satzung, gestellt von den VV-Vorsitzenden Dr. Reiner Zajitschek und Dr. Christian Öttl, die auch im FVDZ-Bundesvorstand sind, erhielt die notwendige ZweiDrittel-Mehrheit. Die wichtigsten Inhalte:

- Der Vorstand der KZVB wird von zwei auf drei Mitglieder erweitert.

- Die Zahl der VV-Delegierten wird in der nächsten Wahlperiode von 27 auf 45 erhöht.

Für die Satzungsänderung votierten in der geheimen Abstimmung 16 von insgesamt 24 anwesenden Delegierten. Die Wahl des dritten Vorstandsmitgliedes ist allerdings erst nach Genehmigung der Änderungen durch die Aufsichtsbehörde möglich.

Ausschlaggebend für die Erweiterung des Vorstandes war für die Delegierten des Freien Verbandes und der regionalen Vereine vor allem die autokratische Amtsführung der letzten Amtsperiode. Die bisherige Regelung, nach der im zweiköpfigen Vorstand bei Stimmengleichheit immer der Vorstandsvorsitzende entscheidet, hatte sich aus Sicht einer deutlichen Mehrheit der Delegierten nicht bewährt. In dem neuen Dreiergremium sind nun auch Mehrheitsentscheidungen möglich.

\section{Mehr Meinungsvielfalt und Demokratie}

Die Vergrößerung der Vertreterversammlung kommt erst in der nächsten Wahlperiode zum Tragen. Der Freie Verband ver-

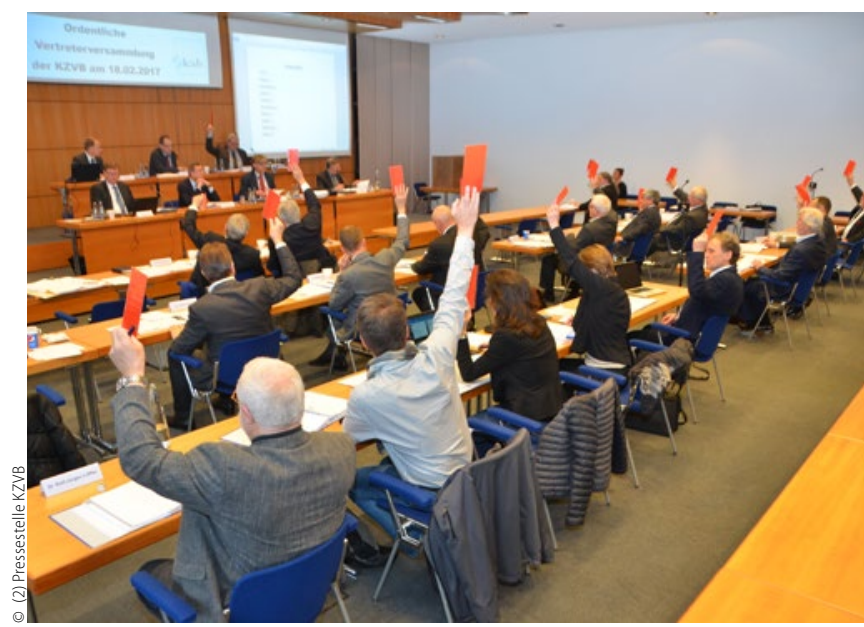

Junge Kolleginnen und Kollegen sollen sich künftig besser in die Standespolitik der bayerischen VV einbringen können. spricht sich hiervon mehr Meinungsvielfalt und mehr Demokratie. Junge Kolleginnen und Kollegen haben nun größere Chancen auf ein Delegiertenmandat und somit die Möglichkeit, sich künftig besser in die bayerische Standespolitik einzubringen.

Darüber hinaus stellte die Vertreterversammlung durch einen fraktionsübergreifenden Antrag klar, dass sie auf eine Präsenz von Ehrenamtsträgern bei Sitzungen des Vorstandes im Sinne einer vertrauensvollen Zusammenarbeit großen Wert legt.

Der politische Leitantrag des Vorstandes für eine bessere Zusammenarbeit von Kammer und KZV in Bayern wurde ebenfalls mit großer Mehrheit verabschiedet. In einer Pressemitteilung der KZVB betonte der neue Vorsitzende des Vorstands Christian Berger, dass er und sein Kollege Dr. Rüdiger Schott bereit seien, Macht abzugeben. „Wir setzen jetzt das um, was wir vor der Wahl versprochen haben“, so Berger. Schott sprach von erheblichen Kommunikationsdefiziten innerhalb der KZVB-Verwaltung. Deshalb sei der Kreis der Personen, die an den Vorstandssitzungen teilnehmen, deutlich erweitert worden. Neben der Geschäftsführung würden nun auch die Geschäftsbereichsleiter, der VV-Vorsitzende und die beiden Referenten des Vorstands zu den Sitzungen eingeladen.

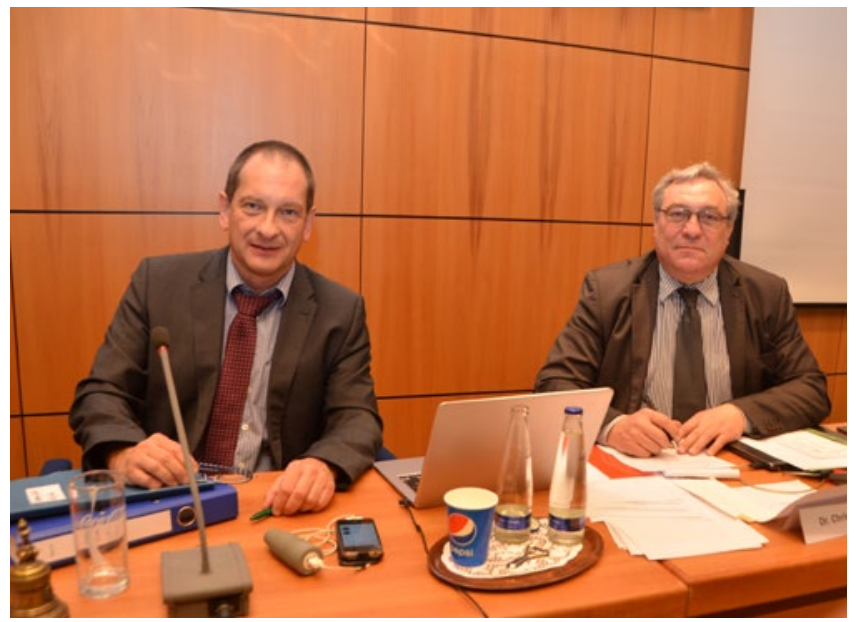

Die VV-Vorsitzenden Dr. Reiner Zajitschek (li.) und Dr. Christian Öttl haben eine Satzungsänderung angestoßen. 